\title{
DAMPAK PEMBANGUNAN RUSUNAWA GUNUNGANYAR TERHADAP KINERJA SIMPANG RUNGKUT MADYA-GUNUNGANYAR SAWAH KOTA SURABAYA
}

\author{
Dwi Muryanto \\ Program Studi Teknik Sipil, Fakultas Teknik, \\ Universitas Dr. Soetomo Surabaya \\ Jl. Semolowaru 84 Surabaya, 60118 \\ Email: dwi.muryanto@unitomo.ac.id
}

\begin{abstract}
Rusunawa Gununganyar is one of the residential area which is estimated to be the center of new activities in 2019 that impacts the trip attraction and trip generation of traffic around it so it needs to be analyzed traffic performance before and after operation. This study aims to determine the traffic performance of the intersection of Rungkut Madya-Gununganyar Sawah which is one of the main access to the location of Rusunawa Gununganyar on the existing condition in 2017, in 2019 after the rusunawa completed and not operational and in 2024 (5 years after the rusunawa operate). This research was analyzed by using Indonesian Highway Manual Capacity (IHCM). Primary data in this study are daily peak hour traffic and geometric conditions intersection surveys, while secondary data is road network and motor vehicle growth rate. Traffic performance analysis begins by calculating traffic volume at peak hour, intersection capacity, and degree of saturation. The result of traffic performance analysis of intersection shows that the degree saturation (DS) value at the existing condition in 2017 is 0,535 , forecast in 2019 is 0,849 , while forecast in 2024 at condition five year after Rusunawa Gununganyar operate is 0,861
\end{abstract}

Keywords: degree of saturation, forecasting, intersection, trip attraction, trip generation

\begin{abstract}
Abstrak
Rusunawa Gununganyar merupakan salah satu kawasan hunian yang diperkirakan menjadi pusat kegiatan baru di tahun 2019 yang berdampak pada tarikan dan bangkitan lalu lintas disekitarnya sehingga perlu dianalisis kinerja lalu lintas sebelum dan sesudah beroperasi. Penelitian ini bertujuan untuk mengetahui kinerja lalu lintas simpang Rungkut Madya-Gununganyar Sawah yang merupakan salah satu akses utama menuju lokasi Rusunawa Gununganyar pada kondisi eksisting tahun 2017, tahun 2019 setelah rusunawa selesai dibangun dan belum beroperasi, tahun 2024 ( 5 tahun setelah rusunawa beroperasi). Penelitian ini dianalisis menggunakan Manual Kapasitas Jalan Indonesia (MKJI) 1997. Data primer dalam penelitian ini adalah arus lalu lintas jam puncak dan kondisi geometrik simpang, sedangkan data sekunder adalah jaringan jalan dan tingkat pertumbuhan kendaraan bermotor. Analisis kinerja lalu lintas dimulai dengan menghitung volume lalu lintas pada jam puncak, kapasitas simpang, dan derajat kejenuhan. Hasil analisis kinerja lalu lintas simpang menunjukkan bahwa derajat kejenuhan (DS) pada kondisi eksisting pada tahun 2017 adalah 0,535, perkiraan pada tahun 2019 adalah 0,849, sedangkan perkiraan pada tahun 2024 pada kondisi lima tahun setelah Rusunawa Gununganyar beroperasi adalah 0,861
\end{abstract}

Kata Kunci: bangkitan perjalanan, derajat kejenuhan, prediksi, simpang, tarikan perjalanan

\section{PENDAHULUAN}

Surabaya merupakan kota yang menjadi pusat kegiatan masyarakat khususnya di Jawa Timur, sehingga banyak pendatang untuk bekerja atau beraktivitas lainnya. Dengan luas wilayah $326,36 \mathrm{~km}^{2}$ dan jumlah penduduk mencapai 3.200.454 jiwa (BPS Kota Surabaya, 2016), aktivitas masyarakat di Kota Surabaya sangat tinggi dan berpengaruh terhadap kondisi lalu lintas ruas jalan maupun persimpangan terutama pada akses menuju pusat-pusat kegiatan akibat adanya bangkitan dan tarikan kendaraan.

Salah satu kawasan yang diperkirakan menjadi pusat kegiatan adalah Rusunawa Gununganyar yang merupakan pusat hunian yang terletak di lokasi sangat strategis, yakni di dekat kawasan pemukiman dan wisata mangrove Kota Surabaya. Diperkirakan dengan beroperasinya Rusunawa Gununganyar akan menarik pergerakan kendaraan menuju ke kawasan tersebut sehingga mengakibatkan padatnya volume lalu lintas kendaraan di sekitar Rusunawa Gununganyar, khususnya Simpang Tidak Bersinyal Rungkut Madya-Gununganyar Sawah yang memiliki lengan pendekat Jl. Rungkut Madya, Jl. Medokan Sawah, Jl. Gununganyar Sawah, dan Jl.
Medokan Asri yang merupakan akses utama menuju lokasi Rusunawa Gununganyar Kota Surabaya.

Adapun maksud dari penelitian ini adalah untuk mengetahui kinerja lalu lintas simpang tidak bersinyal dengan memperoleh gambaran derajat kejenuhan kondisi eksisting tahun 2017, prediksi kinerja lalu lintas simpang tahun 2019 saat Rusunawa Gununganyar selesai dibangun dan belum beroperasi serta prediksi kinerja lalu lintas simpang tahun 2024 setelah Rusunawa Gununganyar beroperasi selama 5 tahun.

\section{TINJAUAN PUSTAKA \\ Persimpangan}

Persimpangan merupakan bagian yang tidak terpisahkan dari semua sistem jalan. Ketika berkendara di dalam kota, orang dapat melihat bahwa kebanyakan jalan di daerah perkotaan biasanya memiliki persimpangan, di mana pengemudi dapat memutuskan untuk jalan terus atau berbelok dan pindah jalan.

Menurut Departemen Perhubungan Direktorat Jenderal Perhubungan Darat (1996), persimpangan adalah 
simpul pada jaringan jalan di mana jalan-jalan bertemu dan lintasan kendaraan berpotongan. Lalu lintas pada masing-masing kaki persimpangan bergerak secara bersama-sama dengan lalu lintas lainnya. Persimpanganpersimpangan merupakan faktor-faktor yang paling penting dalam menentukan kapasitas dan waktu perjalanan pada suatu jaringan jalan, khususnya di daerah-daerah perkotaan.

Karena persimpangan harus dimanfaatkan bersamasama oleh setiap orang yang ingin menggunakannya, maka persimpangan tersebut harus dirancang dengan hatihati, dengan mempertimbangkan efisiensi, keselamatan, kecepatan, biaya operasi, dan kapasitas. Pergerakan lalu lintas yang terjadi dan urutan-urutannya dapat ditangani dengan berbagai cara, tergantung pada jenis persimpangan yang dibutuhkan (C. Jotin Khisty, 2003)

Khisty (2003) menambahkan, persimpangan dibuat dengan tujuan untuk mengurangi potensi konflik diantara kendaraan (termasuk pejalan kaki) dan sekaligus menyediakan kenyamanan maksimum dan kemudahan pergerakan bagi kendaraan.

\section{Jenis-jenis Persimpangan}

Secara umum terdapat tiga jenis persimpangan, yaitu persimpangan sebidang, pembagian jalur jalan tanpa ramp, dan simpang susun atau interchange (Khisty, 2003). Sedangkan menurut F.D. Hobbs (1995), terdapat tiga tipe umum pertemuan jalan, yaitu pertemuan jalan sebidang, pertemuan jalan tak sebidang, dan kombinasi antara keduanya.

Persimpangan sebidang (intersection at grade) adalah persimpangan di mana dua jalan atau lebih bergabung pada satu bidang datar, dengan tiap jalan raya mengarah keluar dari sebuah persimpangan dan membentuk bagian darinya (Khisty, 2003).

\section{Persinggungan di Persimpangan}

Lintasan kendaraan pada simpang akan menimbulkan titik konflik yang berdasarkan alih gerak kendaraan terdapat 4 (empat) jenis dasar titik konflik yaitu berpencar (diverging), bergabung (merging), berpotongan (crossing), dan berjalinan (weaving).

Jumlah potensial titik konflik pada simpang tergantung dari jumlah arah gerakan, jumlah lengan simpang, jumlah lajur dari setiap lengan simpang dan pengaturan simpang. Pada titik konflik tersebut berpotensial terjadinya kecelakaan dan kemacetan lalu lintas.

Pada simpang empat lengan, titik-titik konflik yang terjadi terdiri dari 16 titik crossing, 8 titik diverging dan 8 titik merging seperti ditunjukan dalam Gambar 1.

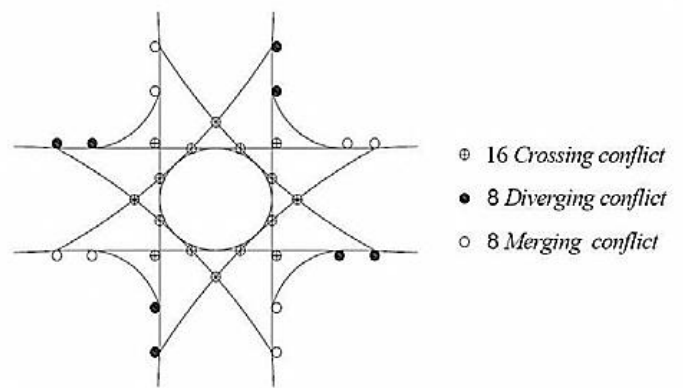

Gambar 1. Titik Konflik pada Simpang Empat Lengan Sumber: Khisty (2003)

\section{Kapasitas (C)}

Kapasitas dapat didefinisikan sebagai arus lalu lintas yang dapat dipertahankan dari suatu bagian jalan atau simpang dalam kondisi tertentu, dalam kendaraan/jam atau smp/jam (MKJI 1997). Kapasitas persimpangan secara menyeluruh dapat diperoleh dengan rumus

$\mathrm{C}=\mathrm{Co} \times \mathrm{FW} \times \mathrm{FM} \times \mathrm{FCS} \times$ FRSU $\times$ FLT $\times$ FRT $\times$ FMI.

dimana:

$$
\begin{array}{ll}
\mathrm{C} & =\text { Kapasitas }(\mathrm{smp} / \mathrm{jam}) \\
\mathrm{Co} & =\text { Kapasitas dasar }(\mathrm{smp} / \mathrm{jam}) \\
\mathrm{FW} & =\text { Faktor koreksi lebar masuk } \\
\mathrm{FM} & =\text { Faktor koreksi tipe median jalan utama } \\
\mathrm{FCS} & =\text { Faktor koreksi ukuran kota } \\
\mathrm{FRSU} & =\text { Faktor penyesuaian kendaraan tak bermotor dan } \\
& \text { hambatan samping dan lingkungan jalan. } \\
\mathrm{FLT} & =\text { Faktor penyesuaian belok kiri } \\
\mathrm{FRT} & =\text { Faktor penyesuaian belok kanan } \\
\text { FMI } & =\text { Faktor penyesuaian rasio arus jalan simpang }
\end{array}
$$

\section{Derajat Kejenuhan (DS)}

Derajat kejenuhan merupakan rasio lalu lintas terhadap kapasitas. Jika yang diukur adalah kejenuhan suatu simpang maka derajat kejenuhan disini merupakan perbandingan dari total arus lalulintas smp/jam) terhadap besarnya kapasitas pada suatu persimpangan (smp/jam). Derajat kejenuhan dapat dihitung dengan menggunakan rumus :

$\mathrm{DS}=\mathrm{Q}_{\mathrm{TOT}} / \mathrm{C}$

dimana:

DS = derajat kejenuhan

C = kapasitas ( $\mathrm{smp} / \mathrm{jam})$

$\mathrm{Q}_{\text {Tот }}=$ jumlah arus total pada simpang $(\mathrm{smp} / \mathrm{jam})$

Tingkat Pelayanan (LOS)

Adapun parameter tingkat pelayanan simpang berdasarkan MKJI 1997 adalah sebagaimana Tabel 1 berikut. 
Tabel 1. Karakteristik Tingkat Pelayanan (Level of Service (LOS) Berdasarkan V/C Atau Derajat Kejenuhan (Degree of Saturation DS).

\begin{tabular}{|c|l|c|}
\hline $\begin{array}{c}\text { Tingkat } \\
\text { Pelayanan }\end{array}$ & \multicolumn{1}{|c|}{ Karakteristik } & $\begin{array}{c}\text { Batas Lingkup } \\
\text { V/C }\end{array}$ \\
\hline A & $\begin{array}{l}\text { Kondisi arus bebas dengan kecepatan tinggi, pengemudi dapat memilih kecepatan } \\
\text { yang dinginkan tanpa hambatan }\end{array}$ & $0,00-0,20$ \\
\hline B & $\begin{array}{l}\text { Arus stabil, tetapi kecepatan operasi mulai dibatasi oleh kondisi lalu lintas, } \\
\text { pengemudi memiliki kebebasan yang cukup untuk memillh kecepatan }\end{array}$ & $0,20-0,44$ \\
\hline C & $\begin{array}{l}\text { Arus stabil, tetapi kecepatan dan gerak kendaraan dikendalikan, pengemudi } \\
\text { dibatasi dalam memilih kecepatan }\end{array}$ & $0,45-0,74$ \\
\hline D & $\begin{array}{l}\text { Arus mendekati tidak stabil, kecepatan masih dikendalikan, V/C masih dapat } \\
\text { ditolerir }\end{array}$ & $0,75-0,84$ \\
\hline E & $\begin{array}{l}\text { Volume lalu lintas mendekati / berada pada kapasitas, arus tidak stabil, kecepatan } \\
\text { terkadang terhenti }\end{array}$ & $0,85-1,00$ \\
\hline F & $\begin{array}{l}\text { Arus yang dipaksakan atau macet, kecepatan rendah, volume diatas kapasitas, } \\
\text { antrian panjang dan terjadi hambatan - hambatan besar }\end{array}$ & $>1,00$ \\
\hline
\end{tabular}

Sumber : MKJI, 1997

\section{METODE PENELITIAN}

\section{Lokasi dan Waktu Penelitian}

Dalam penelitian ini, lokasi yang akan dilakukan perhitungan kinerja lalu lintas adalah Simpang Tidak Bersinyal Rungkut Madya-Gununganyar Sawah yang memiliki lengan pendekat Jl. Rungkut Madya, Jl. Medokan Sawah, Jl. Medokan Asri, dan Jl. Gununganyar Sawah. Simpang ini diambil karena lokasi simpang berada disekitar kawasan pembangunan Rusunawa Gununganyar dan merupakan akses utama menuju kawasan tersebut. Waktu survei lalu lintas dilakukan pada hari aktif. Hari aktif yang diambil adalah hari Selasa dan waktu survei pada pukul 06.00-19.00 WIB.

\section{Tahapan Penelitian}

- Persiapan

Beberapa tahapan dalam penelitian ini adalah:

- Studi literatur

Literatur yang dipakai sebagai aturan dalam menganalisis lalu lintas dan kinerja simpang adalah Manual Kapasitas Jalan Indonesia (MKJI) Tahun 1997 dan Pedoman Kapasitas Jalan Indonesia (PKJI) Tahun 2014

\section{- Survei pendahuluan}

Survei pendahuluan dilakukan di simpang tidak bersinyal Rungkut Madya-Gununganyar Sawah sebagai lokasi penelitian. Dari survei pendahuluan diharapkan bisa ditentukan lokasi titik survei pengumpulan data primer.

- Pembuatan formulir survei perhitungan lalu lintas

- Penentuan jenis data

- Data primer

Volume lalu lintas kendaraan jam puncak dan geometrik simpang tidak bersinyal Rungkut MadyaGununganyar Sawah.

- Data sekunder

Jaringan jalan, angka pertumbuhan kendaraan dan jumlah penduduk Kota Surabaya.

- Pengumpulan data

Data yang dibutuhkan untuk analisis kinerja lalu lintas adalah jumlah kendaraan yang melewati simpang tidak bersinyal Rungkut Madya-Gununganyar Sawah, yakni pada lengan pendekat Jl. Rungkut Madya, Jl. Medokan Sawah, Jl. Gununganyar Sawah, dan Jl. Medokan Asri. Jenis kendaraan yang dihitung adalah sepeda motor
(MC), kendaraan ringan (LV), dan kendaraan berat (HV). Hasil pengumpulan data berupa grafik fluktuasi volume lalu lintas kendaraan yang nantinya bisa digunakan sebagai dasar penentuan jam sibuk (peak hour). Volume lalu lintas saat jam sibuk akan menjadi dasar volume lalu lintas yang akan digunakan dalam analisis kinerja lalu lintas simpang eksisting tahun 2017, prediksi kinerja lalu lintas simpang tahun 2019 saat Rusunawa Gununganyar selesai dibangun tetapi belum beroperasi dan prediksi kinerja lalu lintas simpang tahun 2024 (5 tahun setelah Rusunawa Gununganyar beroperasi).

- Analisis data

Kinerja lalu lintas yang dinilai adalah degree of saturation (DS=derajat kejenuhan) pada simpang tidak bersinyal Rungkut Madya-Gununganyar Sawah. Dari skala waktu, analisis kinerja lalu lintas simpang akan dilakukan 3 (tiga) skala waktu, yakni:

- Kinerja lalu lintas simpang kondisi eksisting tahun 2017

- Kinerja lalu lintas simpang tahun 2019 saat Rusunawa Gununganyar selesai dibangun tetapi belum beroperasi

- Kinerja lalu lintas simpang tahun 2024 (5 tahun setelah Rusunawa Gununganyar beroperasi)

\section{HASIL DAN PEMBAHASAN}

\section{Kinerja Lalu Lintas Simpang Kondisi Eksisting Tahun 2017}

Dari pengumpulan data hasil survei pada simpang tidak bersinyal Rungkut Madya- Gununganyar Sawah, dapat dilakukan analisis kinerja lalu lintas pada simpang tersebut. Hasil analisis kinerja lalu lintas pada simpang tidak bersinyal Rungkut Madya-Gununganyar Sawah pada kondisi eksisting tahun 2017 dapat dilihat pada Tabel 2.

Tabel 2. Hasil Analisis Kinerja Lalu Lintas Simpang Rungkut Madya-Gununganyar Sawah Kondisi Eksisting Tahun 2017

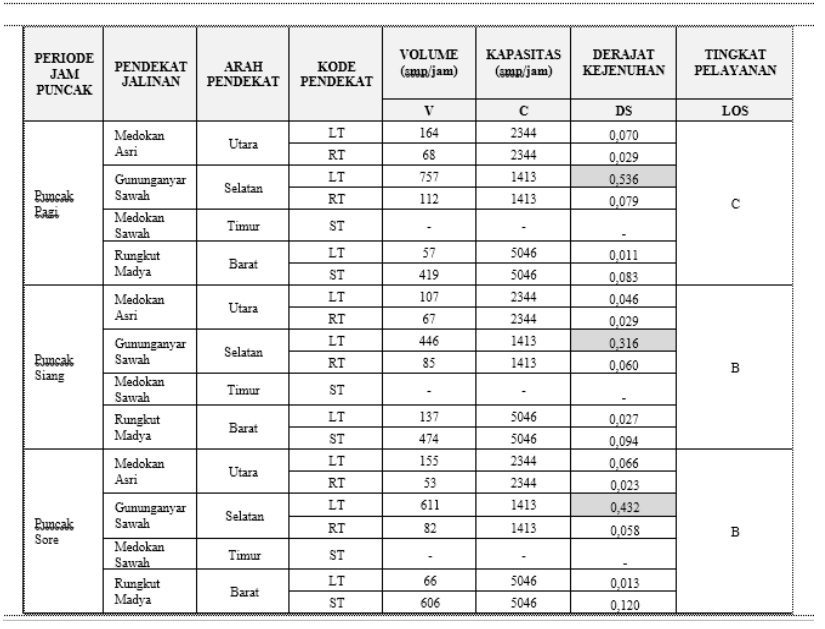

Sumber: Hasil pengolahan data (2017)

Berdasarkan Tabel 2 di atas, dapat diketahui bahwa jam puncak pada simpang tidak bersinyal Rungkut 
Madya-Gununganyar Sawah tahun 2017 terjadi pada pagi hari antara pukul 06.00-09.00 WIB. Hasil analisis kinerja lalu lintas pada simpang tidak bersinyal Rungkut MadyaGununganyar Sawah kondisi eksisting tahun 2017 menunjukkan nilai Degree of Saturation (DS) sebesar 0.536 yang dapat diartikan memiliki kinerja yang baik.

\section{Prediksi Kinerja Lalu Lintas Simpang Tahun 2019 Pada Saat Rusunawa Gununganyar Sudah Selesai Dibangun Dan Belum Beroperasi}

Setelah hasil analisis kinerja lalu lintas simpang tidak bersinyal Rungkut Madya-Gununganyar Sawah pada tahun eksisting diketahui, maka dapat dianalisis perkiraan kinerja lalu lintas simpang tidak bersinyal tersebut pada tahun 2019 saat Rusunawa Gununganyar selesai dibangun dan belum beroperasi.

Prediksi dilakukan dengan peramalan terhadap volume lalu lintas yang terjadi, yaitu dengan cara melakukan analisis terhadap pertumbuhan kendaraan bermotor, dimana angka pertumbuhan (i) berdasarkan pertumbuhan kendaraan bermotor Kota Surabaya. Analisis terhadap pertumbuhan kendaraan bermotor dengan menggunakan rumus:

$$
r=\left\{\left(P_{t} / P_{0}\right)^{(1 / t)}-1\right\} \times 100
$$

dimana :

$$
\begin{array}{ll}
\mathrm{r} & \text { : Laju pertumbuhan kendaraan bermotor }(i) \\
\mathrm{P}_{\mathrm{t}} & \text { : Jumlah kendaraan bermotor pada tahun ke } \mathrm{t} \\
\mathrm{P}_{0} & \text { : Jumlah kendaraan pada tahun dasar } \\
\mathrm{t} & : \text { Selisih tahun Pt dengan Po }
\end{array}
$$

Data untuk menghitung pertumbuhan kendaraan bermotor berdasarkan data sekunder jumlah kendaraan bermotor Kota Surabaya pada Tabel 3.

Tabel 3.. Jumlah Kendaraan Bermotor Kota Surabaya Tahun 2010-2013

\begin{tabular}{|c|c|c|c|c|}
\hline No. & Tahun & LV & HV & MC \\
\hline 1 & 2010 & 368.717 & 2.279 & 1.213 .457 \\
\hline 2 & 2011 & 368.248 & 2.304 & 1.274 .660 \\
\hline 3 & 2012 & 395.739 & 2.486 & 1.402 .190 \\
\hline 4 & 2013 & 444.744 & 2.532 & 1.615 .535 \\
\hline \multicolumn{2}{|c|}{ Jumlah Total } & $\mathbf{1 . 5 7 7 . 4 4 8}$ & $\mathbf{9 . 6 0 1}$ & $\mathbf{5 . 5 0 5 . 8 4 2}$ \\
\hline
\end{tabular}

Sumber: Dinas Perhubungan Kota Surabaya, 2016

Dari hasil analisis data perkembangan jumlah kendaraan bermotor diatas, maka dapat diketahui pertumbuhan (i) kendaraan Kota Surabaya pertahun adalah: $\mathrm{LV}=6,574 \% ; \mathrm{HV}=3,616 \% ; \mathrm{MC}=10,088 \%$. Angka pertumbuhan ini kemudian dijadikan sebagai prediksi pertumbuhan volume lalu lintas. Untuk analisis prediksi kinerja lalu lintas simpang tidak bersinyal Rungkut Madya-Gununganyar Sawah ditahun yang akan datang, maka selanjutnya prosentase pertumbuhan kendaraan tersebut di tambahkan dengan volume kendaraan yang ada pada saat ini di wilayah studi dengan menggunakan rumus:
$\mathbf{P}_{\mathrm{t}}=\mathbf{P}_{\mathbf{0}} \times(1+i)^{\mathrm{n}}$

dimana :

$\mathrm{P}_{\mathrm{t}} \quad$ : Jumlah volume lalu lintas pada tahun ke-t

$\mathrm{P}_{0} \quad$ : Jumlah volume lalu lintas saat ini (eksisting)

$i \quad$ : Laju pertumbuhan jenis kendaraan bermotor

$\mathrm{n} \quad$ : Jumlah tahun peramalan

Setelah mengetahui besaran dari pertumbuhan volume kendaraan, maka selanjutnya untuk prediksi volume dan kinerja lalu lintas simpang tidak bersinyal Rungkut Madya-Gununganyar Sawah tahun 2019 dapat dilihat pada Tabel 4.

Tabel 4. Hasil Analisis Kinerja Lalu Lintas Simpang Rungkut Madya-Gununganyar Sawah Tahun 2019

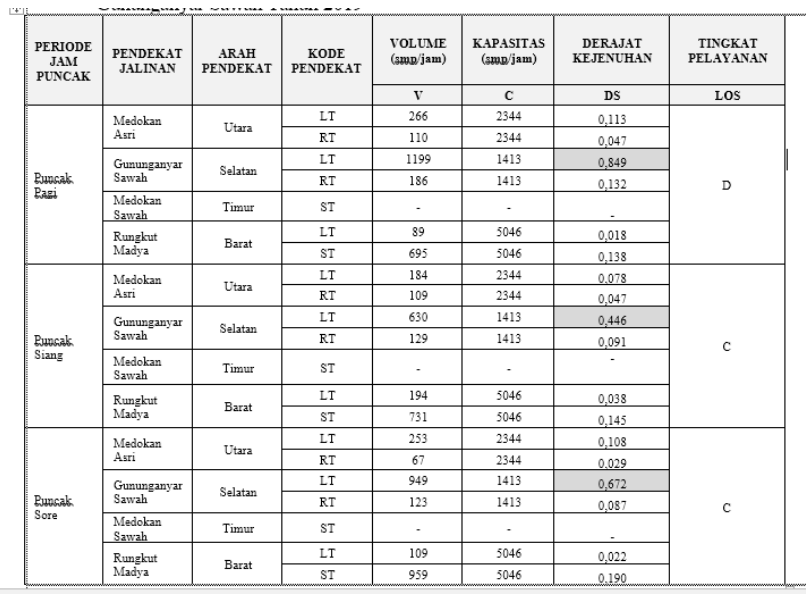

Sumber: Hasil pengolahan data (2017)

Berdasarkan Tabel 4 di atas, dapat diketahui bahwa jam puncak pada simpang tidak bersinyal Rungkut Madya-Gununganyar Sawah tahun 2019 terjadi pada pagi hari antara pukul 06.00-09.00 WIB. Hasil analisis prediksi kinerja lalu lintas pada simpang tidak bersinyal Rungkut Madya-Gununganyar Sawah pada tahun 2019 menunjukkan nilai Degree of Saturation (DS) sebesar 0.849 yang dapat diartikan memiliki kinerja yang kurang baik.

Prediksi Kinerja Lalu Lintas Simpang Tahun 2024 Pada Saat 5 Tahun Rusunawa Gununganyar Sudah Beroperasi

Peramalan lalu lintas dengan adanya pembangunan kawasan bertujuan untuk mengetahui besaran volume dan kinerja lalu lintas yang di prediksi terjadi di tahun-tahun mendatang setelah Rusunawa Gununganyar beroperasi. Analisis prediksi yang dilakukan pada penelitian ini adalah untuk periode tahun 2024, yakni 5 (lima) tahun Rusunawa Gununganyar telah beroperasi sehingga dapat diketahui seberapa besar dampak atau pengaruh beroperasinya Rusunawa Gununganyar terhadap simpang tidak bersinyal Rungkut Madya-Gununganyar Sawah.

Dalam melakukan analisis kinerja lalu lintas simpang digunakan beberapa model perhitungan tergantung pada ketersediaan data yang akan dipergunakan 
dalam proses analisis secara manual. Model perhitungan ini akan memberikan suatu gambaran lalu lintas pada daerah yang akan dilakukan studi. Pendekatan makro dimulai dengan penaksiran intensitas tata guna lahan Rusunawa Gununganyar yang didapatkan dari pengembang/pemrakarsa. Dari data tersebut selanjutnya diestimasi bangkitan perjalanan, distribusi perjalanan dan pembebanan lalu lintas, baik pada jalan-jalan di sekitar lokasi maupun pada akses keluar-masuk lokasi. Pembebanan perjalanan di simpang ditambahkan dengan lalu lintas dasar (base-traffic) tahun rencana (tahun 2024) untuk mendapatkan beban yang nyata pada daerah pengaruh dengan dibangunnya Rusunawa Gununganyar.

\section{Bangkitan Perjalanan}

Pada bangunan Rusunawa Gununganyar secara logika bangkitan perjalanan yang diakibatkan besar mengingat sasaran utama Rusunawa ini adalah hunian dalam satu kawasan/bangunan. Untuk itu faktor bangkitan tarikan sangat diperhitungkan. Tahap awal dari tahapan proses pemodelan (modelling) ini adalah bangkitan perjalanan (Trip Generation) yang dalam hal ini sesuai dengan kategori tata guna lahan daerah mixed used dipergunakan konsep tarikan perjalanan (Trip Attraction).

Dengan mengambil asumsi adanya keterkaitan antara intensitas tata guna lahan dengan jumlah perjalanan keluar masuk lokasi, maka dapat ditentukan hubungan matematis yang menggambarkan tingkat tarikan perjalanan ke lokasi pusat kegiatan tersebut. Adapun model atau teknik asumsi yang digunakan untuk menghitung lalu lintas yang dibangkitkan oleh Rusunawa Gununganyar adalah dengan asumsi perbandingan dari Rusunawa Gunungsari Surabaya, yang mana pada bangunan ini mempunyai karakteristik yang hampir sama yaitu sebagai tempat hunian dan sudah beroperasi.

\section{Analisis Bangkitan Kendaraan}

Berdasarkan data volume bangkitan yang merupakan data rekapitulasi kendaraan masuk dan keluar dari bangunan pembanding dengan besaran jumlah kamar sebagai variable $\mathrm{Y}$ yang nantinya akan dianalisis dengan regresi linear. Bangunan pembanding ini adalah Rusunawa Gunungsari yang terletak di Kelurahan Sawunggaling Kecamatan Wonokromo, dibangun diatas lahan seluas $6.779 \mathrm{~m}^{2}$,bangunan 5 lantai, memiliki 268 unit hunian.

Tabel 5. Data Survei Bangkitan Rusunawa Gunungsari

\begin{tabular}{|c|c|c|c|c|c|c|c|c|c|c|}
\hline \multirow{2}{*}{ Waktu } & \multicolumn{2}{|c|}{ Kendaraan Masuk } & \multirow{2}{*}{$\left.\begin{array}{c}\text { Total } \\
(\mathrm{Smp} / \mathrm{jam})\end{array}\right)$} & \multicolumn{2}{|c|}{ Kendaraan Keluar } & \multirow{2}{*}{$\left.\begin{array}{c}\text { Total } \\
(\mathrm{Smp} / \mathrm{jm})\end{array}\right)$} & \multicolumn{2}{|c|}{ Prosentase Masuk (\%) } & \multirow{2}{*}{\begin{tabular}{|c} 
Prosentas \\
$\mathrm{R} 4$ \\
\end{tabular}} & \multirow{2}{*}{$\begin{array}{c}\text { Keluar (\%) } \\
\text { R2 }\end{array}$} \\
\hline & R & R2 & & R4 & R2 & & RP & $\mathrm{R2}$ & & \\
\hline $06-07$ & 0 & 3 & 1 & 0 & 9 & 2 & 0,00 & 2,61 & 0,00 & 9,47 \\
\hline 07.08 & 1 & 5 & 2 & 0 & 5 & 1 & 3,48 & 4,35 & 0,00 & 5,26 \\
\hline $08-09$ & 1 & 7 & 3 & 1 & 7 & 3 & 3,48 & 6,09 & 4,21 & 7,37 \\
\hline $09-10$ & 0 & 5 & 1 & 1 & 4 & 2 & 0,00 & 4,35 & 4,21 & 4,21 \\
\hline $10-11$ & 1 & 4 & 2 & 0 & 3 & 1 & 3,48 & 3,48 & 0,00 & 3,16 \\
\hline $11-12$ & 0 & 3 & 1 & 1 & 2 & 2 & 0,00 & 2,61 & 4,21 & 2,11 \\
\hline $12-13$ & 0 & 7 & 2 & 0 & 9 & 2 & 0,00 & 6,09 & 0,00 & 9,47 \\
\hline $13-14$ & 0 & 3 & 1 & 0 & 7 & 2 & 0,00 & 2,61 & 0,00 & 7,37 \\
\hline $14-15$ & 1 & 2 & 2 & 1 & 5 & 2 & 3,48 & 1,74 & 4,21 & 5,26 \\
\hline $15-16$ & 0 & 7 & 2 & 0 & 5 & 1 & 0,00 & 6,09 & 0,00 & 5,26 \\
\hline $16-17$ & 1 & 9 & 3 & 1 & 7 & 3 & 3,48 & 7,83 & 4,21 & 7,37 \\
\hline $17-18$ & 0 & 11 & 3 & 0 & 3 & 1 & 0,00 & 9,57 & 0,00 & 3,16 \\
\hline $18-19$ & 0 & 9 & 2 & 0 & 4 & 1 & 0,00 & 7,83 & 0,00 & 4,21 \\
\hline $19-20$ & 1 & 5 & 2 & 0 & 2 & 1 & 3,48 & 4,35 & 0,00 & 2,11 \\
\hline $20-21$ & 1 & 7 & 3 & 0 & 3 & 1 & 3,48 & 6,09 & 0,00 & 3,16 \\
\hline mlah kend/hari & 7 & 87 & 29 & 5 & 75 & 24 & & & & \\
\hline
\end{tabular}

Sumber: Hasil survei (2017)
Tabel 6. Prosentase Kendaraan Keluar Masuk Lokasi

\begin{tabular}{|c|c|c|c|c|c|}
\hline Waktu & Bangkitan & \multicolumn{3}{|c|}{ Prosentase Kendaraan } \\
\hline \multirow{3}{*}{ Puncak } & & \multicolumn{2}{|c|}{ Masuk (\%) } & \multicolumn{2}{|c|}{ Keluar (\%) } \\
\cline { 3 - 6 } Sore & Rusunawa & LV & MC & LV & MC \\
\cline { 3 - 6 } & Gunungsari & 3,48 & 7,83 & 4,21 & 7,37 \\
\hline
\end{tabular}

Sumber: Hasil pengolahan data (2017)

Dari data volume bangkitan dan data jumlah kamar bangunan pembanding, kemudian dilakukan pengolahan data untuk mendapatkan jumlah kendaraan keluar-masuk pada jam puncak pagi. Perhitungan ini menggunakan metode regresi linear

Tabel 7. Jumlah Hunian pada Rusunawa Pembanding dan Rusunawa Gununganyar.

\begin{tabular}{|l|r|l|}
\hline Rusunawa Gununganyar & 252 & Unit \\
\hline Rusunawa Gunungsari & 268 & Unit \\
\hline
\end{tabular}

Sumber : Arsip pengembang (2015)

Hasil analisis dengan metode regresi linear, di dapat persamaan linear seperti pada gambar 2 .

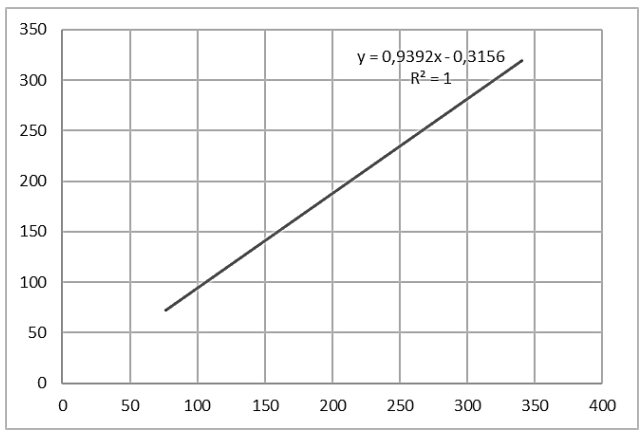

Gambar 2. Grafik Regresi Linier

Sumber: Hasil pengolahan data (2017)

Regresi pembebanan didapat $\mathrm{Y}=0,9392 \mathrm{x}-$ 0,3156. Dengan $\mathrm{x}$ adalah jumlah unit hunian, maka diperoleh pembebanan sebesar 236 smp/jam. Dari hasil perhitungan pembebanan kemudian dihitung asumsi prosentasi kendaraan keluar masuk dari bangunan pembanding yang ditunjukkan pada Tabel 5 diatas. Hasil perhitungan dilakukan untuk mengetahui perkiraan volume kendaraan yang akan keluar masuk pada tiap arah Rusunawa Gununganyar.

Tabel 8. Distribusi Bangkitan

\begin{tabular}{|c|c|c|c|c|c|}
\hline Waktu & Bangkitan & \multicolumn{4}{|c|}{ Prosentase Kendaraan } \\
\hline & & \multicolumn{3}{|c|}{ Masuk (\%) } & \multicolumn{2}{c|}{ Keluar (\%) } \\
\cline { 3 - 6 } & & LV & MC & LV & MC \\
\cline { 3 - 6 } & & 3,48 & 7,83 & 4,21 & 7,37 \\
\hline \multirow{2}{*}{ Puncak } & Jumlah Bangkitan & \multicolumn{5}{|c|}{$236 \mathrm{smp} / \mathrm{jam}$} \\
\hline Sore & Distribusi Bangkitan & 8 & 18 & 10 & 17 \\
\hline
\end{tabular}

Sumber: Hasil pengolahan data (2017)

Selanjutnya jumlah bangkitan dan tarikan kendaraan tersebut disebarkan disetiap pergerakan kendaraan pada simpang tidak bersinyak Rungkut MadyaGununganyar Sawah berdasarkan proporsi volume kendaraan tiap zona perjalanan yang ada pada saat ini 
sehingga didapat volume dan kinerja lalu lintas simpang 2024 seperti pada Tabel 9.

Tabel 9. Hasil Analisis Kinerja Lalu Lintas Simpang Tidak Bersinyal Rungkut Madya-Gununganyar Sawah Tahun 2024 (5 Tahun Setelah Rusunawa Gununganyar Beroperasi)

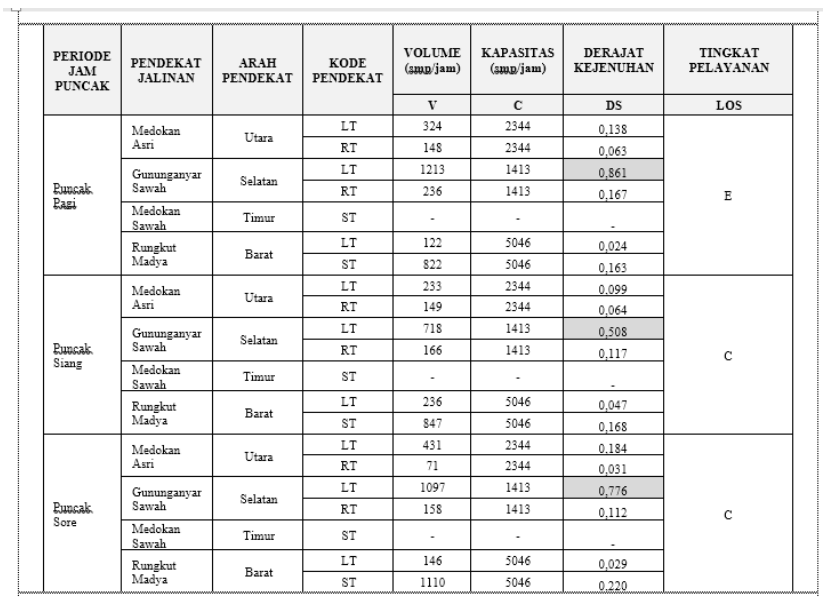

Sumber: Hasil pengolahan data (2017)

Berdasarkan Tabel 9 di atas, dapat diketahui bahwa jam puncak pada simpang tidak bersinyal Rungkut Madya-Gununganyar Sawah pada tahun 2024, yakni setelah 5 tahun Rusunawa Gununganyar beroperasi terjadi pada pagi hari antara pukul 06.00-09.00 WIB. Hasil analisis kinerja lalu lintas pada simpang tidak bersinyal Rungkut Madya-Gununganyar Sawah pada tahun 2024 menunjukkan nilai Degree of Saturation (DS) sebesar 0.861 yang dapat diartikan memiliki kinerja yang kurang baik.

\section{KESIMPULAN}

Didapatkan beberapa kesimpulan dalam penelitian ini, diantaranya:

- Pada kondisi eksisting tahun 2017 nilai Derajat Kejenuhan (DS) simpang tidak bersinyal Rungkut Madya-Gununganyar Sawah 0,536 atau $\leq 0,75$, yang dapat diartikan memiliki kinerja lalu lintas baik.

- Pada tahun 2019 kondisi Rusunawa Gununganyar sudah terbangun dan belum beroperasi didapat nilai Derajat Kejenuhan (DS) simpang tidak bersinyal Rungkut Madya-Gununganyar Sawah 0,849 atau $\geq$ 0,75 , yang dapat diartikan memiliki kinerja lalu lintas kurang baik.

- Pada tahun 2024 yaitu 5 tahun setelah Rusunawa Gununganyar beroperasi nilai Derajat Kejenuhan (DS) simpang tidak bersinyal Rungkut Madya-Gununganyar Sawah 0,861 atau $\geq 0,75$, yang dapat diartikan memiliki kinerja lalu lintas kurang baik.

- Jam puncak tertinggi pada semua kondisi terjadi pada pagi hari antara pukul 06.00-09.00 WIB.

\section{REFERENSI}

Badan Pusat Statistik. (2016). Kota Surabaya Dalam Angka 2016, Biro Pusat Statistik, Kota Surabaya

Departemen Pekerjaan Umum. (1997). Manual Kapasitas Jalan Indonesia, Direktorat Jenderal Bina Marga, Jakarta

Hidayat, B. dan Mitra, N.S. (2014). Analisis Dampak Lalu Lintas (Pengaruh Pembangunan Terhadap Lalu Lintas), Edisi 01, Aura Pustaka. Yogyakarta.

Huda, M. dan Muryanto, D. (2016). “Analisis Kinerja Lalu Lintas Sebelum dan Setelah Pembangunan Blitar Town Square". Jurnal Rekayasa Teknik Sipil Universitas Madura. Vol.1, No.2, Desember 2016, Hal 7-10, Fakultas Teknik, Universitas Madura, Pamekasan.

Kementerian Pekerjaan Umum. (2014). Modul Pedoman Kapasitas Jalan Indonesia, Direktorat Jenderal Bina Marga, Jakarta.

Kementerian Perhubungan. (2015). Permenhub Nomor: PM 75 Tahun 2015 Tentang Analisis Dampak Lalu Lintas, Direktorat Jenderal Perhubungan Darat, Jakarta.

Miro, F. (2012). Pengantar Sistem Transportasi, Edisi 15, Erlangga, Jakarta.

Qadhafi, M. (2016). "Analisis Dampak Lalu Lintas Pembangunan Hotel Tunjungan Kota Surabaya". Skripsi, Fakultas Teknik Universitas Dr. Soetomo, Surabaya. 